\title{
Changes of Insulation Properties of Photovoltaic Cables Caused by Ageing Treatment
}

\author{
Juraj Packa, Vladimír Kujan, Daniel Štrkula, Vladimír Šály and Milan Perný \\ Slovak University of Technology, Faculty of Electrical Engineering and Information Technology, \\ Institute of Power and Applied Electrical Engineering, Bratislava, Slovak Republic, \\ e-mail: juraj.packa@stuba.sk
}

\begin{abstract}
An important part of the photovoltaic power plants are cable systems. The dielectric properties of cables, reliability and durability depend on quality of production processes, operating conditions and degradation factors, as well. Expected lifetime of the cable systems is more than 20 30 years in general. Their failure free operation and longterm stability of properties has a direct impact on the economic return of the investments. According to our experiences the tests in compliance with valid standards are not adequate to verify the real life time during operation. The photovoltaic cables intended for use in outdoor applications for the connection between the solar panels and possible connection between panels and inverter were chosen for our experiments. The changes of the insulation resistance and breakdown voltage caused by some degradation factors, mainly water, are presented. This research was inspired by a real failure in operation.
\end{abstract}

Keywords - photovoltaics, cables, insulation resistance, breakdown voltage, water, ageing, degradation factors

\section{INTRODUCTION}

The insulation of the photovoltaic (PV) systems (modules, devices, cables and their interconnection) operates under the influence of usual environmental factors. It is designed to be UV resistant and rated for wet locations. It can be used within a large temperature range from $-40{ }^{\circ} \mathrm{C}$ to $125^{\circ} \mathrm{C}$.

The cable system is an integral and very important part of the solar power plants. Cable reliability and long-term stability is determined by the quality level of production processes, by multitude of operating factors and depends also on the cables installation. It is important for safety, service and economic return of investment. Moreover costs of repair are much higher on occurrence of an unexpected failure combined with losses caused by a shutdown of the PV plants. Therefore information about the properties of the insulating materials, ageing factors and understanding of the mechanisms of failure under operating conditions, diagnostic methods and the criteria for replacement of the cable systems are necessary [1-3].

Under ageing, the performance of the cable insulation is changing gradually. Ageing affects the properties in small or large volumes of the insulation. Some property changes may take several years to develop while others occur within weeks or years, e.g. thermo-mechanical ageing due to overload condition [4].
Of course we can expect that a longer cable route will face a larger risk of breakdown than a short route.

The ageing factors are usually divided into four groups: thermal ageing, electrical ageing, mechanical ageing and environmental ageing. These factors may combine into multi stress situation and cause to accelerate a further ageing. The most important stresses for the photovoltaic cables in normal operating conditions are electrical and thermal stresses under UV radiation, water and humidity.

Water and humidity can enter into the cable insulation through the cable termination (i.e. through connector), pin-holes in the jacket, by water vapour transmission through the jacket or other ways.

It is a well-known fact that the dielectric performance and ageing resistance get worse under the influence of water. It should be noted that polymeric materials are often completely water-tight but still allow the humidity diffusion [5-8].

The standard [9] provides test methods primarily intended to permit the observation of the effect of high humidity at a constant temperature. Preferred test durations are 12,16 or 24 hours and $2,4,10,21$ or 56 days, respectively.

According to our experiences, mentioned tests cannot reliably replace long-term tests and long-term effects of the degradation factors during operation.

Conventionally used non-destructive integral diagnostic method is the test of insulation resistance. It can be carried out in situ. The dc test set is relatively simple, low cost and weighty. Good insulation shows a continuous increase of the resistance over a period of time (time-resistance testing method is from 1 to 10 minutes). If the insulation contains moisture or contaminants, the absorption effect is masked by a high leakage current which stays at a fairly constant value and so the insulation resistance does. But the limit value for this parameter is not specified by manufacturers.

The ageing of the insulation is often ascertained in terms of the breakdown voltage of the aged specimens in laboratory conditions.

It is a wide spread to compare the chosen properties of the aged cables with their initial values obtained at the original virgin state.

\section{SPECIMENS UNDER OPERATION IN PV POWER PLANT}

Our research was inspired by a real failure in operation. Failures of cables for photovoltaic application in a PV 
power plant occur after one year operation, see Fig. 1. Photovoltaic cables were buried in perforated pipe during operation. The supposed main degradation factor was water and humidity.

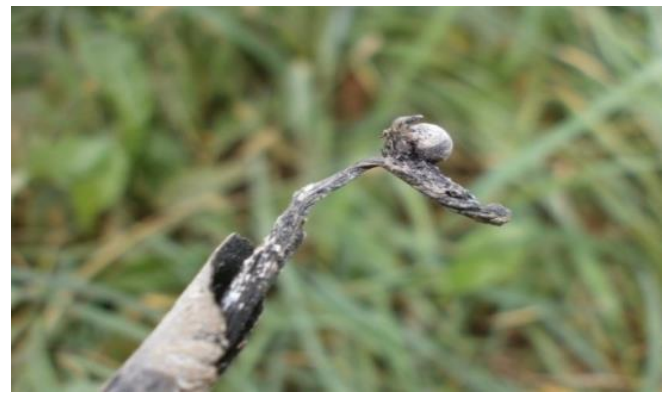

Fig. 1. Failures of photovoltaic cable in PV solar plant occur after one year operation.

The cables from the PV solar plant operation were from two different manufacturers (marked A and B). This type of cables is intended for use in outdoor applications for the connection between the solar panels and possible connection from them to the inverter. The cables were one core copper tinned cables, nominal cross section $2.5 \mathrm{~mm}^{2}$ with rated voltage $1.8 \mathrm{kV}$ dc or $1.0 \mathrm{kV}$ ac. The insulating material is halogen free, flame, ozone, UV resistant and was made of cross-linked polyolefin. The specimens had a double-insulated structure. The expected lifetime of the cables is more than 25-30 years.

The time dependences of the measured insulation resistance of cables of the same type and different manufactures after one year operation in PV power plants are shown in Fig 2. The measurement was performed in the laboratory at ambient temperature. Regarding one core and no screen metal specimens were immersed in water during the measurement.

In general, a high value of the insulation resistivity indicates a good condition of the insulation system. As the insulation system accumulates dirt, moisture and as the insulation ages and cracks, the value of the insulation resistivity decreases.

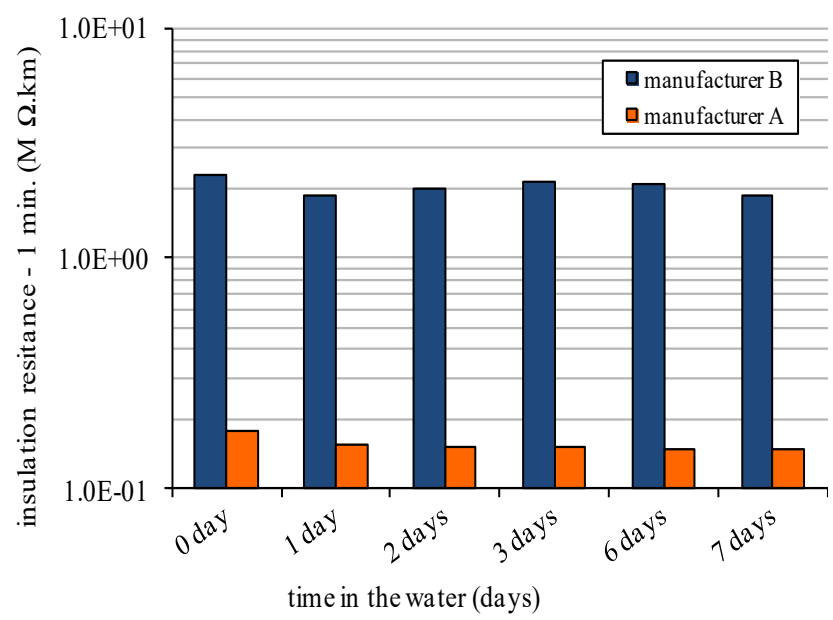

Fig. 2. Time dependence of the insulation resistance of photovoltaic cables after one year operation [10].

Fig. 2 shows much lower insulation resistance of the specimen A in comparison with B.
That is why the specimen of the manufacturer A was chosen for our next experiment: new cables (virgin state) - marked A-N and cables after one year operation in the photovoltaic power plant - marked A-O. Three meter long specimens were subjected to the water immersing test in our laboratory. There was measured time dependence of the insulation resistance at ambient temperature during 7 days (marked D). Afterwards the specimens were dried in the air thermostat for 48 hours at $80{ }^{\circ} \mathrm{C}$ and measured again during 74 days immersed in water (marked $\mathrm{P}$ ).

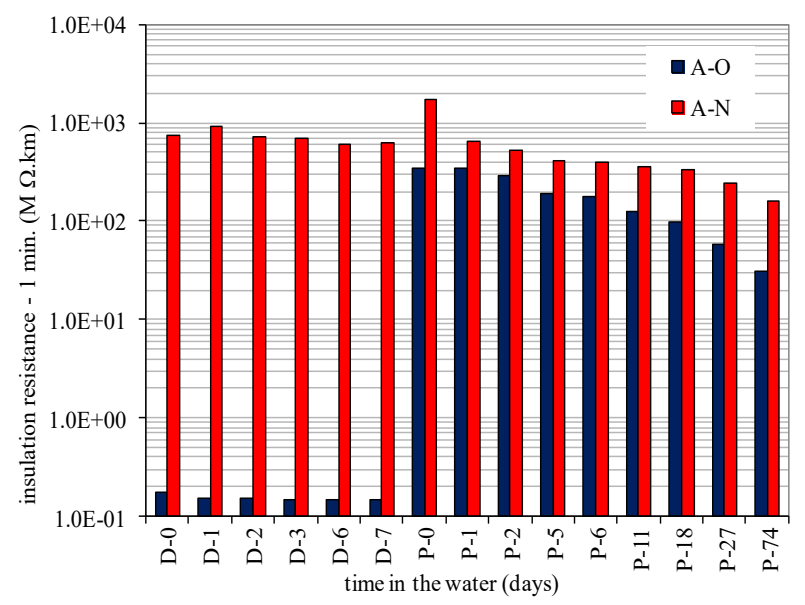

Fig. 3. Time dependence of the insulation resistance in water before (D) and after $(\mathrm{P})$ drying [11]

Initial measurements show a wide value difference of the insulation resistance between the specimens A-O and A-N (marked D). After drying in an air thermostat we can see significant changes of the measured parameter of the cable after one year operation (marked $\mathrm{P}$, specimens A-O). Depending on the immersion time in water (P-0 $\mathrm{P}-74)$ a gradual decrease of the insulation resistance of the specimen after one year operation (A-O) occurs after drying, in comparison with new cable specimen (A-N) which is more stable.

Despite of improvement of the insulation resistance immediately after drying ( $\mathrm{P}-0)$ there was an irreversible damaged insulation of the cable after one year operation. The insulation resistance depending on time of reimmersion in water ( $\mathrm{P}-0-\mathrm{P}-74)$ is much more sensitive on the specimen after one year operation (A-O) in comparison with new cable (A-N) [11].

\section{COMPARISON OF DIFFERENT SPECIMENS TREATEDIN LABORATORY CONDITIONS}

The photovoltaic cables of two manufacturers (marked A and B), mentioned above, were also subjected to our proposed "procedure of ageing" in laboratory conditions, specified below.

The specimens of both manufacturers were exposed to the increased temperature $100{ }^{\circ} \mathrm{C}$ during 40, 65 and 122 days. Consequently, the specimens were immersed in water for 62 days. Measurements of the insulation resistance in the range of temperature from 23 to $65^{\circ} \mathrm{C}$ were performed during first and last 5 days. After the first measurement at $23{ }^{\circ} \mathrm{C}$ the temperature was set to an increased value and then kept for next 24 hours. Our "procedure ageing" was performed by Keithley 617 Programmable Electrometer at $100 \mathrm{~V}$ dc. Moreover, a 
voltage $1000 \mathrm{~V}$ ac was applied during 21 days (between $7^{\text {th }}$ and $28^{\text {th }}$ day).

The influence of thermal ageing on the insulation resistance measured during first 5 days in water is shown in Fig.4.

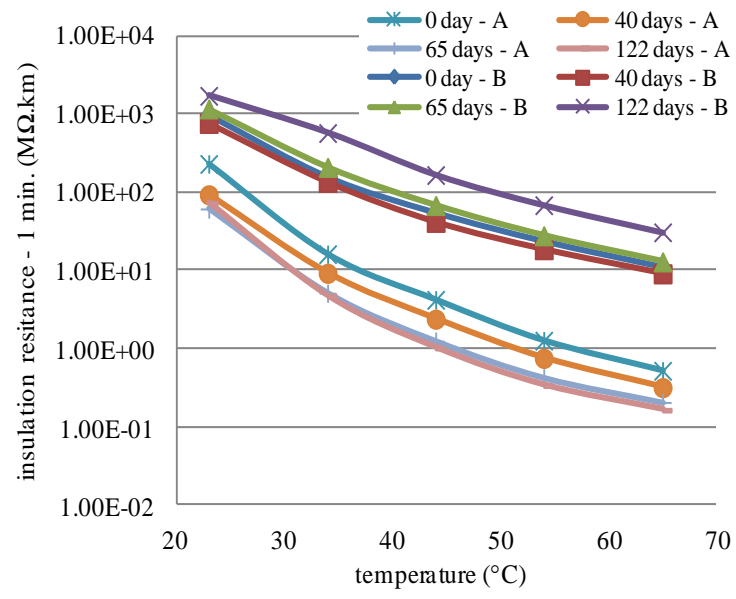

Fig. 4. Temperature dependence of the insulation resistance of photovoltaic cables during first 5 days in water.

The influence of water on the insulation resistance measured during last 5 days in water is shown in Fig.5.

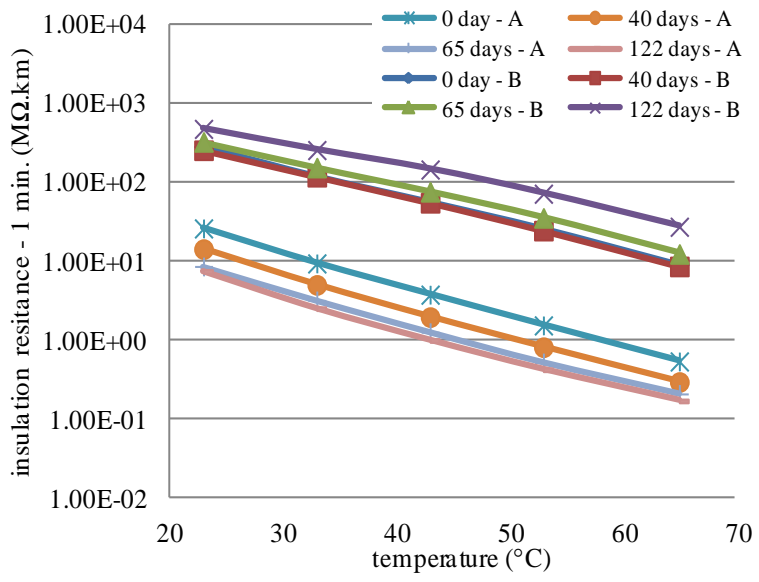

Fig. 5. Temperature dependence of the insulation resistance of photovoltaic cables during last 5 days in water.

Figures 4 and 5 show apparent distribution of the measured characteristic depending on the manufacturers. The performance of cables of the manufacturer $B$ is better in comparison with cables of the manufacturer A. The measured characteristics reveal the influence of time of the thermal ageing in case of the manufacturer $\mathrm{A}$. The insulation resistance decreases when the time of thermal ageing increases. On the other side these changes are not significant.

As an interesting result we can conclude that the measured properties of the specimens B after 65 and 122 days thermal ageing are improved in comparison with those after 40 days and the original virgin state. Perhaps it can be caused by drying of the specimens. On the contrary drying of the specimen after 40 days can be masked by a retraction sheath [3].
Time dependence of the insulation resistance during the ageing procedure in water at ambient temperature is depicted in Fig.6.

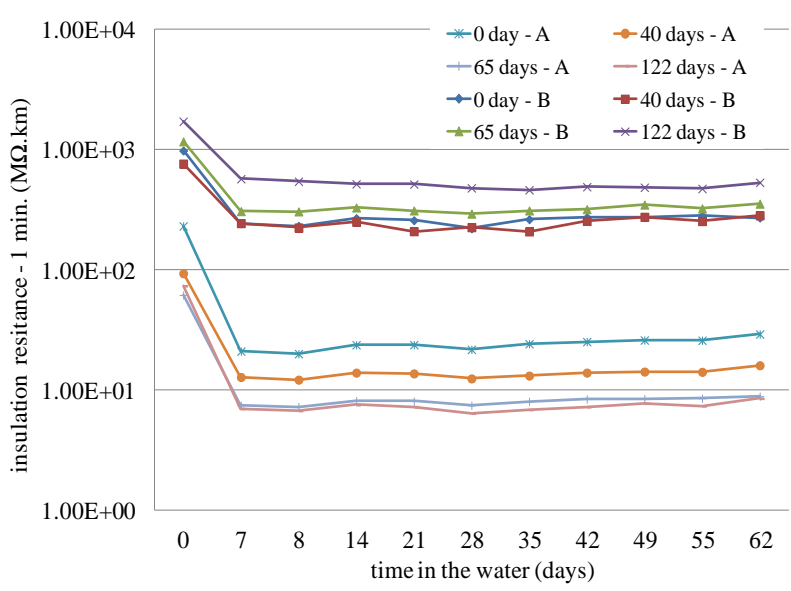

Fig. 6. Time dependence of the insulation resistance during the "procedure ageing" in water.

As we can see in Fig. 6, the insulation resistance was decreasing during first 7 days and then was stable in the case of both manufacturers. The behaviour was similar even between $7^{\text {th }}$ and $28^{\text {th }}$ days when the voltage 1000 ac was applied. The cables of the manufacturer $B$ have higher insulation resistance in comparison with cables of the manufacturer A during whole "procedure ageing". The applied voltage with level $1000 \mathrm{~V}$ ac has no influence in the case of both manufactures.

The aim of our next experiments was to verify and compare the breakdown voltage of the specimens from both manufacturers after our "procedure ageing".The breakdown voltage value testis the most important experiment linked to lifetime of cable in laboratory conditions. The breakdown voltage test results can be used for detecting changes from the ageing conditions. The inner electrode was the core of the cable and as outer electrode a band of metal foil $25 \mathrm{~mm}$ wide was used.

Due to the high values of the breakdown voltage, this measurement was carried out with the specimens immersed in silicon oil with continuously rising voltage at ambient temperature.

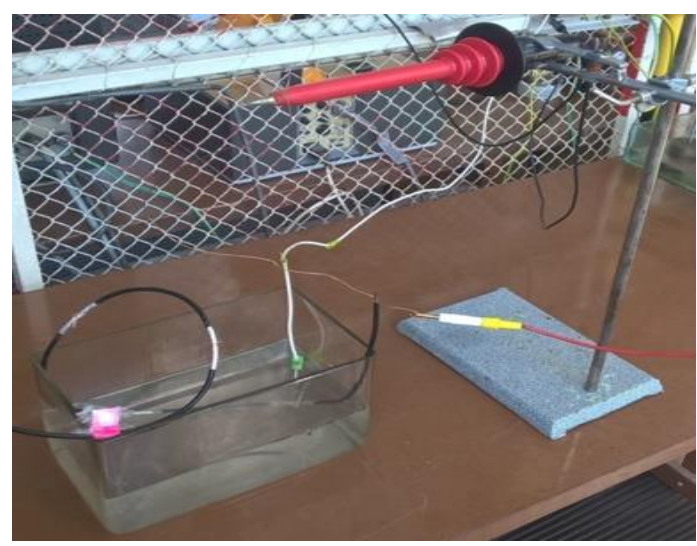

Fig. 7. Measuring workplace of the breakdown voltage.

As we can see in Fig. 8, the thermal ageing does not play important role regarding the values of the breakdown 
voltage of both manufacturer specimens. The observed differences can be attributed to statistical dispersion in individual measurements of the breakdown voltage. The chart depicts the average values of five measurements. A similar situation is in the case of the manufacturer B at the "procedure ageing", as well.

On the contrary, the breakdown voltage decreases for about $50 \%$ in the case of specimens of the manufacturer A after the "procedure ageing". Those are very significant changes of the measured property.

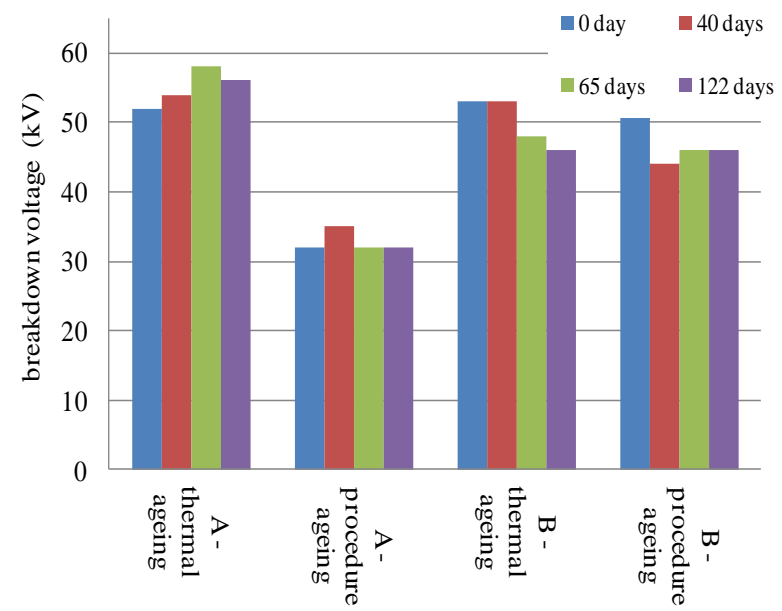

Fig. 8. Breakdown voltage of the measured specimens after the thermal ageing and "procedure ageing" (water, voltage stress) at ambient temperature.

\section{CONCLUSION}

Our research was inspired by a real failure in operation. Failures of the cable for photovoltaic application in PV solar plant occurred after one year operation. Photovoltaic cables were buried in a perforated pipe during operation. The main degradation factors were water and humidity.

That was why the photovoltaic cables of two manufacturers were subjected to the "procedure ageing" proposed specially for laboratory conditions. Degradation factors as water, temperature and voltage were applied. The conventionally used diagnostic method for this type of the cable - insulation resistance was performed, as well as the breakdown voltage test.

According to obtained results we can find the difference between cables delivered by two manufacturers. The differentiation of the insulation resistance characteristic depending on the manufacturers is apparent. The specimens of the manufacturer B were in better condition. The breakdown voltage decreased for about $50 \%$ in case of the manufacturer A specimens after our "procedure ageing". On the contrary, changes of the breakdown voltage were not observed at the manufacturer $B$ specimen.
Comparison of the impacts of degradation factors on specimens of photovoltaic cables after one year operation (Fig. 2) and during tests in the laboratory conditions (Fig. 6) shows similar conclusions.

The measured values of insulation resistance confirmed better resistance to degradation effects (water, voltage, temperature) of specimens $\mathrm{B}$ in comparison with specimens A.

\section{ACKNOWLEDGMENT}

This work was supported by the Slovak Research and Development Agency under the contract No. APVV-150326, No. APVV-15-0108 and No. APVV-15-0110.

\section{REFERENCES}

[1] A. A. Al-Arainy, A. A. Ahaideb, M I. Qureshi, and N.H. Malik, "Statistical Evaluation of Water Tree Lengths in XLPE Cables at Different Temperatures," IEEE Transactions on Dielectrics and Electrical Insulation, Vol. 11, No. 6, December 2004, pp. 9951006. https://doi.org/10.1109/TDEI.2004.1387823

[2] Ch. Dang, J. L. Parpal, and J. P. Crine, "Electrical aging of extruded dielectric cables review of existing, theories and data," IEEE Transactions on Dielectrics and Electrical Insulation, Vol. 3 No. 2, April 1996, pp. 237-247. https://doi.org/10.1109/94.486776

[3] S. B. Dalal, R. S. Gorur, and M. L. Dyer, "Aging of distribution cables in service and its simulation in the laboratory," IEEE Transactions on Dielectrics and Electrical Insulation, Volume: 12, Issue: 1, February 2005, pp. 139-146. https://doi.org/10.1109/TDEI.2005.1394024

[4] J. Densley, "Ageing mechanisms and diagnostics for power cables - An Overview," IEEE Electrical Insulation Magazine, Vol. 17, No. 1, 2001, pp. 14 - 21. https://doi.org/10.1109/57.901613

[5] Y.T. Hsu, K.S. Chang-Liao, T.K. Wang, and C.T. Kuo, "Monitoring the moisture-related degradation of ethylene propylene rubber cable by electrical and SEM methods," Polymer Degradation and Stability, 91, 2006, pp. 2357-2364. https://doi.org/10.1016/j.polymdegradstab.2006.04.003

[6] J. China, A. Forster, C. Clerici, L. Sung, M. Oudina, and K. Rice, "Temperature and humidity aging of poly (p-phenylene-2,6benzobisoxazole) fibers," Chemical and physical characterization Polymer Degradation and Stability, 92, 2007, pp. 1234-1246. https://doi.org/10.1016/j.polymdegradstab.2007.03.030

[7] C. Katz, G.W. Seman, and B.S. Bemstein, "Low temperature aging of XLPE and EP insulated cables with voltage transients," IEEE Transactions on Power Delivery, Vol. 10, No. 1, January 1995, pp. 34-42. https://doi.org/10.1109/61.368418

[8] S.V. Nikolajevic, "The behavior of water in XLPE and EPR cables and its influence on electric characteristics of insulation," IEEE Transactions on Power Delivery, Vol. 14, No. 1, January 1999, pp. 39-45. https://doi.org/10.1109/61.736677

[9] STN EN 60068-2-78: Environmental testing. Part 2-78: Tests. Test Cab: Damp heat, steady state, 2013.

[10] J. Packa, V. Kujan, D. Štrkula, V. Šály, and M. Váry, “The influence of selected degradation factors on the dielectric properties of cables for photovoltaic applications," In Renewable Energy Sources 2016, Tatranské Matliare, Slovakia, 2016, pp. 110-113.

[11] J. Packa, and V. Š́ly, "The Influence of water and humidity on the cable insulation electric characteristics for photovoltaic applications," In Renewable Energy Sources 2013, Tatranské Matliare, Slovakia, May 21-23, 2013, pp. 443-446. 